\title{
O AQUECIMENTO GLOBAL COMO NOVO FUNDAMENTALISMO ECONÔMICO: REFLEXÕES SOBRE O DISCURSO AQUECIMENTISTA
}

Felipe Almeida dos Santos*

Clara Ribeiro Silva**

\begin{abstract}
Resumo: O presente artigo tem por objetivo debater os pressupostos econômicos existentes na hipótese do aquecimento global. Para tanto, o aquecimento global é considerado aqui não como consenso científico, mas um discurso político e econômico que busca (e tem obtido êxito significativo) se constituir em um novo fundamentalismo, expresso na consolidação de um "novo" mercado de consumo, de reprodução de capitais e de controle ao desenvolvimento de nações emergentes. Dessa forma, foram utilizados os pressupostos da climatologia geográfica a fim de caracterizar o clima global como sistema dinâmico, e da geografia política como meio de identificar os interesses do discurso aquecimentista como ideologia política e econômica, fundamentada no alarmismo ambiental de matriz neomalthusiana.
\end{abstract}

Palavras-chave: Aquecimento global; Fundamentalismo econômico; Climatologia; Geopolítica;

\begin{abstract}
This article aims to discuss the existing economic assumptions in the global warming hypothesis. Therefore, global warming is seen here not as a scientific consensus, but a political and economic discourse that seeks (and has achieved significant success) constitute a new fundamentalism, expressed in the consolidation of a "new" consumer market, reproduction capital and control the development of emerging nations. Thus, the assumptions of geographic climatology were used to characterize the global climate as a dynamic system, and political geography as a means of identifying the interests of aquecimentista speech as political and economic ideology, based on environmental alarmism neomalthusiana matrix.
\end{abstract}

Keywords: Global Warming; Economic Fundamentalism; Climatology; Geopolitics.

\footnotetext{
* Licenciado, Bacharel pelo Centro Universitário Sant'Anna; Mestre em Geografia pela PUC/SP. Professor do curso de geografia do Centro Universitário Sant'Anna.

"* Graduanda do curso de bacharelado em Geografia da Universidade Federal de Alfenas UNIFAL-MG.
} 


\section{O AQUECIMENTO GLOBAL COMO NOVO FUNDAMENTALISMO ECONÔMICO: REFLEXÕES SOBRE O \\ DISCURSO AQUECIMENTISTA \\ Felipe Almeida dos Santos \& Clara Ribeiro Silva}

\section{Introdução}

O aquecimento global está hoje dentre os temas ditos científicos mais repercutidos nos meios de comunicação, ocupando inclusive importante espaço em campanhas publicitárias e programas de reestruturação do mercado consumidor. De controvérsia científica até o final da década de 1990, o discurso aquecimentista foi transformado em verdade inquestionável e/ou consenso irrefutável a partir da publicação da $15^{\mathrm{a}}$ sessão do IPCC (do inglês Painel Intergovernamental sobre Mudanças Climáticas), na qual foram empregados os métodos para elaboração dos relatórios sobre mudanças do clima. Desde então, uma hipótese não consensual foi tornada cenário de alarmismo global, capaz de suscitar as mais mitológicas narrativas de fim dos tempos, sob o álibi do aumento das temperaturas globais que resultaria no derretimento de geleiras, glaciares e calotas polares, acarretando na elevação do nível dos mares, em secas, estiagens dentre outros cenários catastróficos que todos, direta e indiretamente, já ouviram dizer.

O discurso aquecimentista, transformado em verdade científica inabalável, possibilitou a formação de um fértil espaço de reorganização do capital, em especial da rearticulação de padrões de consumo e formação de novos mercados consumidores, a partir da criação de uma indústria do aquecimento global, da qual será tratada adiante.

Assim, este artigo busca discorrer sobre a influência do discurso aquecimentista na reorganização dos padrões de consumo, considerado aqui como estratégia de consolidação de um "novo" fundamentalismo econômico em que o lobby sustentável ocupa papel central não somente na formação de novos mercados, mas como estratégia de ocultar as consequências do capitalismo sobre o planeta, criando assim uma saída a tais consequências no interior do próprio capitalismo, como se fosse possível haver um capitalismo sustentável.

Como pressuposto teórico, o clima será tratado neste trabalho não de forma estáticoestatística, mas como fenômeno dinâmico e variável, dotado de variabilidades que se manifestam no tempo e espaço, e que as ciências da atmosfera ainda pouco têm de respostas nesses pouco mais de cem anos de pesquisas sistemáticas de natureza teórico-quantitativas.

Desta forma, este artigo buscou realizar revisão bibliográfica sobre a temática do alarmismo instituído pelo discurso aquecimentista. Para tanto, foram utilizados os pressupostos da climatologia geográfica e da geografia política, respectivamente, a fim de caracterizar o clima global como sistema dinâmico e identificar os interesses do discurso aquecimentista como ideologia política e 


\section{O AQUECIMENTO GLOBAL COMO NOVO FUNDAMENTALISMO ECONÔMICO: REFLEXÕES SOBRE O \\ DISCURSO AQUECIMENTISTA \\ Felipe Almeida dos Santos \& Clara Ribeiro Silva}

econômica, fundamentada no alarmismo ambiental de matriz neomalthusiana, que se constitui hoje como um novo fundamentalismo.

\section{Pressupostos da hipótese aquecimentista}

Os questionamentos acerca das consequências das relações sociedade e natureza na modernidade muito antecedem os argumentos que consideram a atmosfera como a primeira grande impactada pelo desenvolvimento da sociedade capitalista. Segundo Porto-Gonçalves (2011), o movimento ambientalista tem raízes na luta indigenista em defesa dos povos originários e seus territórios saqueados desde o período colonial e, posteriormente, no seio do movimento socialista do século XIX, ganhando novo peso ao final dos anos 1960 com o chamado movimento de "contracultura", surgido como questionamento aos padrões de consumo e comportamento, do qual se destacam o movimento hippie, o feminista, o anarquista e também o ambientalista, já como caracterização moderna da luta contra as consequências ambientais da sociedade capitalista.

A força e o crescimento dos questionamentos quanto às consequências do capitalismo surgidos da "contracultura", em especial do movimento ambientalista, exigiram das grandes corporações e das nações desenvolvidas representadas pela ONU (Organização das Nações Unidas) uma série de ações na tentativa de desmobilizar e descaracterizar tais movimentos. Vale lembrar que o movimento ambientalista foi capaz de consolidar uma importante frente de luta contrahegemônica do qual se incorporavam as lutas ecológica, feminista, antirracista, pacifista e socialista.

A partir daí os questionamentos acerca da sociedade urbano-industrial e seu modelo de desenvolvimento são retomados em outros marcos por conferências e tratados internacionais, que surgem como estratégias para canalizar a crítica dos movimentos de "contracultura", em especial o movimento ambientalista, já consolidado por sua oposição ao modelo predatório de produção capitalista.

Exemplo disso são as reuniões anteriores a esse período, como a Conferência das Nações Unidas sobre conservação dos recursos naturais, convocada em 1948, como proposta de intercâmbio de experiência de reconstrução de áreas devastadas pela Segunda Guerra. Tal fato explicita os diferentes interesses por trás do discurso de preservação do meio ambiente instituído 


\section{O AQUECIMENTO GLOBAL COMO NOVO FUNDAMENTALISMO ECONÔMICO: REFLEXÕES SOBRE O \\ DISCURSO AQUECIMENTISTA \\ Felipe Almeida dos Santos \& Clara Ribeiro Silva}

pelas nações desenvolvidas, nesse período, com objetivo específico de expandir o capital estadunidense na Europa pós-guerra, por meio da adoção do plano Marshall.

Em contraponto, já com outros interesses geopolíticos, o discurso de proteção ao meio repercute no interior da Organização das Nações Unidas no final da década de 1960 a partir do chamado Clube de Roma. Fundado em 1966 pela elite industrial e científica europeia estadunidense, esse grupo produziu documentos, entre eles o "Relatório do Clube de Roma", que discursa sobre o futuro desenvolvimento das sociedades, a preocupação com o meio ambiente, crescimento populacional e recursos naturais. Entretanto, pode-se observar que esses argumentos a partir da publicação do relatório "Os Limites do Crescimento", em 1972, não buscam substituir o atual modelo de desenvolvimento, mas sim dar-lhe uma nova "roupagem", como os cinco eixos de uma suposta crise de esgotamento de recursos devido ao crescimento exponencial de população, produção de alimentos, industrialização e poluição pela interação do homem com a natureza, sendo assim mais um exemplo de neomalthusianismo.

Os relatórios e discursos constituídos pelos cientistas e industriais em torno de uma suposta preocupação com as questões do meio ambiente foram um dos fatores para a criação da Conferência das Nações Unidas sobre o Meio Ambiente Humano, também conhecida como Conferência de Estocolmo, realizada entre os dias 5 e 16 junho de 1972, em Estocolmo, capital da Suécia, considerada o primeiro encontro entre chefes de Estados que deu início às discussões sobre o meio ambiente em escala global. Nota-se que esta preocupação com o futuro está diretamente relacionada ao avanço do desenvolvimento tecnológico, a possível escassez dos recursos não renováveis e o aumento populacional no planeta. Esta conferência é um importante marco devido à produção da Declaração sobre Ambiente Humano, apresentando 29 princípios a serem seguidos, visando novos valores para preservação do meio ambiente. Neste documento, é possível analisar a separação entre os países chamados "desenvolvidos" e os "em desenvolvimento", o "norte" e o "sul".

Com forma de avaliar as ações definidas no relatório final da Conferência de Estocolmo, foi criada a Comissão Mundial Sobre Meio Ambiente e Desenvolvimento, entre 1983 e 1986. Esta comissão elaborou relatórios que culminaram nos apontamentos acerca do efeito estufa (aquecimento global) e o "buraco" na camada de ozônio, dando origem ao IPCC (Painel sobre Mudanças Climáticas, sigla do inglês).

Retomados posteriormente na chamada Cúpula da Terra, ou Rio-92 (Eco-92), realizada na cidade brasileira do Rio de Janeiro, os apontamentos acerca da chamada crise ambiental. Dentre os 


\section{O AQUECIMENTO GLOBAL COMO NOVO FUNDAMENTALISMO ECONÔMICO: REFLEXÕES SOBRE O \\ DISCURSO AQUECIMENTISTA \\ Felipe Almeida dos Santos \& Clara Ribeiro Silva}

inúmeros encaminhamentos ali consolidados está inserida a Convenção sobre mudança do Clima, discutida e ratificada em setembro de 1997 em Quioto, Japão, e intitulada "Protocolo de Quioto".

Tal acordo, aberto para assinaturas a partir de dezembro de 1997 e ratificado em março de 1999, somente entrou em vigor em 2005, após a assinatura da Rússia no ano anterior, garantindo assim a participação de 55 países responsáveis pela produção de $55 \%$ das emissões de $\mathrm{CO} 2 \mathrm{em}$ escala global. Assim, o protocolo passou a instituir um conjunto de metas de redução de emissões, levando em conta o estágio de desenvolvimento das nações. Tais metas poderiam ser negociadas em um mercado mundial de "carbono", no qual capitais financeiros internacionais passariam a ocupar um importante papel de negociação para compra de títulos de projetos de energia limpa, de cotas de emissão, de projetos de sustentabilidade e principalmente, criação de um novo mercado consumidor a partir de investimentos em publicidade de empresas e Estados Nação, tendo como suposto objetivo reduzir a temperatura global entre $1,4^{\circ} \mathrm{C}$ e $5,8^{\circ} \mathrm{C}$ até 2100 .

Criada em 1988 pela Organização Mundial das Nações Unidas, a Intergovernmental Panel on Climate Change (IPCC) apresenta-se com o objetivo de realizar estudos cientificamente comprovados acerca do aquecimento global. A principal afirmação dos cientistas é que o aumento da temperatura média global está relacionado diretamente com as emissões de gases poluentes na atmosfera lançados pela ação humana, havendo um aumento a partir da Revolução Industrial, e entre os principais gases estaria o vilão dióxido de carbono $(\mathrm{CO} 2)$.

Mesmo com pouco aprofundamento nos conceitos da climatologia geográfica e um consenso científico entre a relação dos gases e o comportamento climático, criou-se um alarde midiático que prevê mudanças climáticas e situações catastróficas do planeta Terra caso os países industrializados e principalmente as nações em desenvolvimento não diminuam ou cessem a utilização de combustíveis fósseis e a emissão de $\mathrm{CO} 2$ na atmosfera. A ideia é que passem, assim, a adotar alternativas de cotas de emissão do dióxido de carbono e de energia limpa, como a energia solar, eólica e hidroeletricidade. Seu fácil convencimento está relacionado aos sumários escritos pelo IPCC (Sumário para os Formuladores de Política), de linguagens menos complexas, apresentando relatórios avaliativos que caracterizam os impactos sobre o clima:

\footnotetext{
As concentrações atmosféricas globais de dióxido de carbono, metano e óxido nitroso aumentaram bastante em consequência das atividades humanas desde 1750 e agora ultrapassam em muito os valores pré-industriais determinados com base em testemunhos de gelo de milhares de anos. Os aumentos globais da concentração de dióxido de carbono se devem principalmente ao uso de combustíveis fósseis e à mudança no uso da terra. Já os aumentos da concentração de metano e óxido nitroso são devidos principalmente à agricultura. (IPCC, 2007: p. 03).
} 


\section{O AQUECIMENTO GLOBAL COMO NOVO FUNDAMENTALISMO ECONÔMICO: REFLEXÕES SOBRE O \\ DISCURSO AQUECIMENTISTA \\ Felipe Almeida dos Santos \& Clara Ribeiro Silva}

A partir das discussões aquecimentistas surgem personalidades e políticos motivados pela preocupação com futuro e conservação do planeta. Entre eles, destaca-se o vice-presidente norte americano Al Gore, durante a presidência de Bill Clinton entre os anos de 1999 e 2003 e derrotado na disputa presidencial em 2000 por George W. Bush. Sua imagem apelativa em torno dos discursos aquecimentistas tomou grande repercussão midiática a partir de palestras em diversos países e pelo documentário "Uma Verdade Inconveniente" (em inglês, An Inconvenient Truth, 2006) sobre as mudanças climáticas, que lhe rendeu o Prêmio Nobel da Paz, em 2007. O documentário é organizado pela exposição de gráficos e planilhas em "slides", além de imagens e animações catastróficas e comoventes a fim de convencer e sensibilizar o mundo acerca do suposto consenso aquecimentista antrópico. Em seu documentário, Al Gore destaca que a emissão desenfreada de gases poluentes durante o século XX, como o $\mathrm{CO} 2$, é responsável pelo aumento da temperatura global, causando futuramente o derretimento de geleiras, tempestades, furacões, secas e aumento do nível do mar, criando-se assim uma "crise climática". Como solução e reversão deste nefasto e assustador problema ambiental, o político induz novas práticas e hábitos de consumo mundial, tecnologia verde e sustentável, além de acordos políticos como o crédito de carbono e a não industrialização de países que buscam o desenvolvimento.

Em contrapartida, durante o ano de 2009, os principais noticiários do mundo publicaram reportagens sobre a possibilidade de fraude nos dados do IPCC em pesquisas que comprovariam o aumento da temperatura global. Esses indícios foram anunciados a partir do acesso de "hackers" no e-mail da Unidade de Pesquisa Climática da Universidade East Anglia, Inglaterra, onde o cientista Phil Jones demonstra sua atuação na manipulação dos dados climáticos em relatórios do IPCC e seus resultados nos modelos matemáticos induzidos a legitimar o pressuposto aquecimento (LINO, 2009).

\section{O aquecimento global como falso consenso científico}

A hipótese aquecimentista, propagada como irrefutável consenso científico, do qual gigantesco aporte de recursos provenientes de Estados-Nação, organizações internacionais e empresas globais contratam, financiam e direcionam pesquisas e resultados, criou uma hegemonia no meio científico capaz de isolar, reprimir e perseguir todos os cientistas que a ela se contrapõem. A hegemonia aquecimentista se consolida não só na excessiva veiculação midiática, mas também no 


\section{O AQUECIMENTO GLOBAL COMO NOVO FUNDAMENTALISMO ECONÔMICO: REFLEXÕES SOBRE O \\ DISCURSO AQUECIMENTISTA \\ Felipe Almeida dos Santos \& Clara Ribeiro Silva}

direcionamento do financiamento científico, restrito e até mesmo inexistente para aqueles que se contrapõem ao aquecimento global. Assim, publicar trabalhos e pesquisas contrárias à hipótese aquecimentista é tarefa árdua, quase impossível (MARUYAMA, 2009). Ainda assim, tem crescido significativamente o grupo de pesquisadores contrários ao aquecimento global, recorrentemente chamados de céticos.

Diversos são os questionamentos acerca da hipótese aquecimentista, sobretudo após a publicitação da manipulação de dados realizada em 2009 por pesquisadores do IPCC, a fim de direcionar os resultados das pesquisas que comprovariam a elevação das temperaturas em escala global. Tal fato intensificou as críticas ao IPCC, já realizadas anteriormente no ano de 2007, quando um grupo de pesquisadores manipulou dados utilizados em 2001, a fim de corrigir uma curva de variação das temperaturas globais registradas em um gráfico climático, dando origem ao episódio intitulado de "taco de hóquei" (LINO, 2009).

Tais evidências de manipulação se somam às críticas referentes à ausência de séries climáticas confiáveis que antecedam os últimos 150 anos, uma vez que as pesquisas sobre a atmosfera anteriores ao começo do século XX eram restritas a poucos países, dentre eles França, Reino Unido, Estados Unidos e Alemanha. Assim, as séries temporais sobre o clima são reduzidas e fragmentadas, o que inviabiliza qualquer tentativa de apontar projeções que antecedam uma centena de anos (BAPTISTA, 2009). É somado ainda o fato de essas séries climáticas serem compostas por estações meteorológicas localizadas anteriormente em áreas rurais e, hoje, estarem no centro de grandes áreas urbanas, constituídas por superfícies que elevam a temperatura da atmosfera devido ao efeito das ilhas de calor, alterando assim significativamente as médias de temperatura, que devido ao crescimento das cidades, são registradas muito mais elevadas desde o começo da segunda metade do século XX (BAPTISTA, 2009).

Shigenori Maruyama, destacado paleoclimatologista japonês, questiona os métodos empregados pelo IPCC, em especial pela forma com que os dados meteorológicos de diferentes latitudes, hemisférios, continentes e regiões do globo são empregados, padronizados e embutidos em um único método de análise matemática, os chamados modelos, desconsiderando as especificidades de cada local onde esses dados foram registrados:

[...]as temperaturas dos últimos mil anos não devem ter sido medidas com as mesmas técnicas em todos os países. Correspondem a valores estimados por diferentes pesquisadores que utilizam diferentes metodologias, como anéis de crescimento das árvores; características da sedimentação; razões isotópicas de oxigênio ou outros isótopos 


\section{O AQUECIMENTO GLOBAL COMO NOVO FUNDAMENTALISMO ECONÔMICO: REFLEXÕES SOBRE O \\ DISCURSO AQUECIMENTISTA \\ Felipe Almeida dos Santos \& Clara Ribeiro Silva}

estáveis de carbono, cujas idades são medidas por radiocarbono, pois as paleotemperaturas são estimadas por isótopos de elementos químicos; análise de palinomorfos (pólen + esporo). (MARUYAMA, 2009 p.23)

Luis Carlos Molion, um dos mais respeitados climatologistas do Brasil, ex-membro do IPCC, representante dos países da América do Sul na Comissão de Climatologia da Organização Meteorológica Mundial (OMM) e uma das mais conhecidas vozes contrárias à hipótese aquecimentista, questiona a tese de que o aumento aproximado de $0,7^{\circ} \mathrm{C}$ na temperatura média global seja decorrente da intensificação do efeito estufa, uma vez que a variabilidade natural do clima representa alterações cíclicas muito superiores a esses valores (MOLION, 2007).

Para ele, não há fundamento no argumento de que o CO2 é o grande regulador do clima global. Segundo Molion (2008), o Sol é o grande regulador do clima global, e as atividades solares apresentam um ciclo de aproximadamente 90 anos entre a máxima e mínima intensidade.

Por fim, Molion (2007) questiona a forma como as séries históricas dos últimos 150 anos são interpretadas pelos pesquisadores do IPCC:

$\mathrm{Na}$ realidade, as características desses registros históricos conflitam com a hipótese do efeito-estufa intensificado. O Planeta se aqueceu mais rapidamente entre 1925- 1946, quando a quantidade de $\mathrm{CO} 2$ lançada na atmosfera era inferior a $10 \%$ da atual, e se resfriou entre 1947-1976, quando ocorreu o desenvolvimento econômico acelerado após a Segunda Guerra Mundial. (MOLION, 2007, p.9)

Assim, em dezembro de 2007, um grupo de mais de 100 cientistas, dentre físicos, climatologistas, meteorologistas, geógrafos, geólogos, entre outros, redigiu uma carta aberta ao Secretário-Geral das Nações Unidas, sob o título "Conferência climática da ONU conduz o mundo a uma direção inteiramente errada". A referida carta buscou contra-argumentar os apontamentos publicados no sumário de 2007 do IPCC a partir dos seguintes aspectos:

(1) Recentes observações de fenômenos como diminuição de glaciares, aumento do nível do mar e a migração de espécies sensíveis à temperatura não são provas de mudanças climáticas anormais, não tendo sido demonstrado que qualquer mudança tenha ocorrido fora dos limites da variabilidade natural. (2) A média de aquecimento de 0,1 a $0,2^{\circ} \mathrm{C}$ por década registrada por satélites durante o final do século XX se enquadra numa taxa natural de resfriamento e aquecimento observada ao longo dos últimos dez mil anos.

(3) Cientistas proeminentes, incluindo alguns dos mais importantes pesquisadores do IPCC, reconhecem que hoje os modelos climáticos computadorizados não conseguem prever o clima. Com base nisso, e apesar das projeções de aumento da temperatura, não houve aumento bruto da temperatura do planeta desde 1998. A estabilização da temperatura segue um período de aquecimento registrado no final do século XX que é consistente com os 
ciclos naturais multidecadais e milenares do clima. (4) Em contraste com a afirmação feita repetidamente de que a ciência do clima é hoje incontroversa, importantes trabalhos peer-reviewed trouxeram ainda mais dúvidas quanto à hipótese de um perigoso aquecimento induzido pelo homem. Mas porque os grupos de trabalho do IPCC foram induzidos a considerar trabalhos publicados apenas até maio de 2005, estas revelações importantes não estão incluídas nos relatórios e, assim, as conclusões do IPCC já estão desatualizadas. (LINO, 2009, p.125)

O referido documento tem como signatários de destaque os cientistas Ernst-Georg Beck, Freeman J. Dyson, Vicente Gray, Craig D. Idso, Sherwood B. Idso, Zbigniew Jawarowski, Marcel Leroux, Richard Lindzen, Ross McKitrick, Gart W. Paltridge, S. Fred Singer, Edward J. Wegman, além dos renomados brasileiros Luiz Carlos Molion, Kenitiro Suguio, José Bueno Conti, Fernando de Mello Gomide, dentre outros.

O discurso aquecimentista, mediante inúmeros questionamentos e refutações, ainda assim se constituí como pressuposto hegemônico sobre o clima, e se materializa nas ações políticas e econômicas como uma espécie de inquisição, como bem define Baptista (2009), uma vez que os interesses por trás dessa concepção assumem uma radicalidade que rompe a premissa científica, se fazendo dogma, a exemplo dos fundamentalismos que veem na diferença o inimigo a ser combatido, a fim de manter sua hegemonia discursiva e existencial.

\section{O aquecimento global como "novo" fundamentalismo econômico}

O discurso aquecimentista, antes de se consolidar como uma nova indústria econômica de reprodução do capital, é instituído como argumento ecológico de legitimação da intervenção dos Estados Nacionais e do poder econômico-financeiro ao movimento de contracultura, em especial aos grupos que a partir da década de 1960 se organizavam em questionamento à ausência de liberdades individuais, a questões de gênero, ao consumismo, à guerra, ao racismo e, principalmente, à chamada crise ambiental, fundamentada na exploração predatória dos recursos da natureza (PORTO-GONÇALVES, 2011).

Sem generalizações acerca da essência dos diversos movimentos surgidos na chamada contracultura, principalmente nas nações desenvolvidas da Europa e nos EUA, o movimento ambientalista foi certamente o que mais gerou algum tipo de preocupação direta à hegemonia capitalista, em especial à sua capacidade de articulação de diferentes frentes de luta. Assim, sob a 


\title{
O AQUECIMENTO GLOBAL COMO NOVO FUNDAMENTALISMO ECONÔMICO: REFLEXÕES SOBRE O \\ DISCURSO AQUECIMENTISTA \\ Felipe Almeida dos Santos \& Clara Ribeiro Silva
}

tutela da ONU, diversas reuniões de chefes de Estado foram realizadas a fim de criar meios para canalizar os discursos consolidados pelo movimento ambientalista, do qual se destacam o chamado Clube de Roma e a proposta da Conferência das Nações Unidas sobre o Meio Ambiente Humano, Estocolmo 1972. A partir daí, a tentativa de direcionar as críticas dos movimentos sociais para um suposto discurso oficial de toda comunidade internacional representada pela ONU é somada a necessidade de consolidação de novos mercados de consumo em escala global, principalmente por ser esse período caracterizado como uma transição do capitalismo, conforme defendido por Harvey:

\begin{abstract}
A acumulação flexível, como vou chamá-la, é marcada por um confronto direto com a rigidez do fordismo. Ela se apoia na flexibilidade dos processos de trabalho, dos mercados de trabalho, dos produtos e padrões de consumo. Caracterizando-se pelo surgimento de setores de produção inteiramente novos, novas maneiras de fornecimento de serviços financeiros, novos mercados e, sobretudo, taxas altamente intensificadas de inovação comercial, tecnológica e organizacional. A acumulação flexível envolve rápidas mudanças dos padrões de desenvolvimento desigual, tanto entre setores como entre regiões geográficas, criando, por exemplo, um vasto movimento no chamado "setor de serviços", bem como conjuntos industriais completamente novos em regiões até então subdesenvolvidas[...]. (HARVEY, 2014, p.140)
\end{abstract}

Harvey (2014), ao caracterizar a perda de hegemonia do sistema de acumulação e regulação fordista (integralmente centralizado na indústria como produtora única de bens e serviços), especialmente a partir da saturação dos mercados internos centrais e a necessidade de novos mercados de exportação dos excedentes, propõe que a acumulação flexível, constituída como novo sistema de reprodução do capital no que se refere à acumulação e regulação, se materialize não apenas como uma ruptura da centralização fabril a partir do surgimento de uma imensa rede de serviços, mas também como nova forma de fragmentação do espaço no plano da individualidade, onde padrões de consumo são instituídos pelo desenvolvimento de um novo mercado estéticocultural.

Nesse novo padrão de consumo constituído pela condição pós-moderna (HARVEY, 2014) está situada a chamada sustentabilidade, que segundo Löwy (2014), é, na realidade, uma manifestação do ecocapitalismo, que busca se constituir enquanto uma "nova" forma de reprodução do capital em uma suposta versão humanizada e consciente, como se fosse possível um capitalismo não predatório.

Dentre todo o discurso ambientalista incorporado pelas nações desenvolvidas e grandes corporações internacionais representadas pela ONU, a hipótese do aquecimento global é 


\section{O AQUECIMENTO GLOBAL COMO NOVO FUNDAMENTALISMO ECONÔMICO: REFLEXÕES SOBRE O \\ DISCURSO AQUECIMENTISTA \\ Felipe Almeida dos Santos \& Clara Ribeiro Silva}

consensualmente a de maior destaque político e midiático, se constituindo assim como a maior estratégia para a consolidação dos interesses geopolíticos e econômicos descritos anteriormente.

De falso consenso científico, o discurso aquecimentista, considerado dogma e verdade irrefutável, uma nova inquisição, como afirma Baptista (2009), ou, como caracterizado aqui, um novo fundamentalismo, não apenas de caráter discursivo, mas de plano econômico de reprodução do capital, se institui como importante estratégia de consolidação de um novo mercado de consumo em escala global. Este é necessário para territorialização de grandes instituições econômicas em novos espaços, por meio de projetos de desenvolvimento sustentável, energias limpas, financiamento a corporações "ambientalmente corretas", e principalmente, da consolidação de políticas que reduzam o crescimento das chamadas nações emergentes, a exemplo da China, Rússia, Índia e Brasil.

A existência de um mercado aquecimentista já não é novidade no espaço econômico internacional. Desde o final da década de 1980 existe um crescente processo de mercantilização da atmosfera em torno das patentes dos chamados gases CFC (clorofluorcarboneto). Somente após o fim dos chamados direitos de produção é que esse composto gasoso foi considerado um vilão para a atmosfera (LINO, 2009). A isso somam-se ainda os chamados créditos de carbono, pelos quais organismos de financiamento internacional, a exemplo do Banco Mundial e do FMI (Fundo Monetário Internacional), seriam responsáveis pela criação de fundos para a comercialização de percentuais de redução de emissões, seja por meio da compra e venda, ou da abertura de crédito para o fomento de energias limpas. Lino (2009) aponta ainda que, até 2014, o mercado de carbono alcançaria o patamar de maior mercado de commodities do mundo, atingindo uma soma aproximada de 2 trilhões de dólares anuais.

Baptista (2009), ao caracterizar os reais beneficiados com a indústria aquecimentista, afirma:

Os beneficiados com a teoria do aquecimento global são os ricos e poderosos. Os perdedores são o resto do mundo. As soluções encontradas para minimizar os efeitos do aquecimento global apoiam-se conceitualmente numa corrente chamada de modernização ecológica, que, segundo Henri Acseraldo, se baseia na internacionalização das preocupações ambientais por parte de instituições políticas, que visam conciliá-las com o crescimento econômico. Isso é possível por meio da adoção de tecnologias ditas "limpas". Mas elas normalmente são caras e inacessíveis aos pobres. Uma coisa é a Alemanha reunificada adotar tecnologias ambientalmente corretas, outra coisa é Moçambique adotálas. (BAPTISTA, 2009, p.167) 


\section{O AQUECIMENTO GLOBAL COMO NOVO FUNDAMENTALISMO ECONÔMICO: REFLEXÕES SOBRE O \\ DISCURSO AQUECIMENTISTA \\ Felipe Almeida dos Santos \& Clara Ribeiro Silva}

Assim, o discurso sustentável ou a tese da sustentabilidade se constitui como estratégia de manutenção da hegemonia do capital, em relação à canalização dos movimentos divergentes, em especial ao ambientalista, e à possibilidade de consolidação de um novo mercado de produção e consumo em escala global, possibilitando a expansão geográfica do capital que, segundo Harvey (2014), é considerada um importante mecanismo de superação das crises do capitalismo geradas pela superacumulação. Desta forma, a chamada acumulação flexível altera o tempo de giro da produção, ao criar consumos de baixa duração que logo são substituídos, gerando assim mais produção e, em consequência, acumulação (HARVEY, 2014)

Esse novo mercado, constituído em sua gênese como descentralização do processo fabril, sobretudo a partir da expansão de uma imensa rede de serviços, constituídos em sua maioria da relação entre ciência e produção (os chamados avanços técnicos ou tecnológicos), se apresenta no discurso aquecimentista (e ambientalista) por meio das chamadas fontes energéticas e tecnologias limpas, dos produtos sustentáveis, da eficiência produtiva e principalmente do consumidor consciente. A partir daí é que o discurso aquecimentista (o mais radical no interior do movimento ambientalista ecocapitalista) se constitui como um novo fundamentalismo, uma vez que, caracterizado como dogma científico, é feito verdade inquestionável, capaz de direcionar todo o mercado produtivo e de consumo sob o álibi sustentável.

Esse processo, que nada tem a ver com o necessário questionamento ao capitalismo como modelo de sociedade insustentável, predatório e desigual, se materializa como um importante instrumento ideológico de alienação das massas que, pautado no catastrofismo, institui novos padrões de consumo e comportamento para os cidadãos, e novas condições de bloqueio ao crescimento e desenvolvimento das nações emergentes e subdesenvolvidas. Assim, esse discurso representa um fundamentalismo econômico, considerado condição imutável ou via única de superação da chamada crise ambiental.

Por fim, o discurso do aquecimento global pode ser caracterizado como ideologia hegemônica da atualidade, a partir de dois campos específicos do fundamentalismo.

O primeiro, mais visível, portanto, identificável, é formado pela criação de novos padrões de consumo, pela intensificação do consumismo em escala global (em especial a partir da estratégia de canalização da crítica ambientalista para um novo padrão de consumo). Este consumismo, apesar de nova roupagem, rotulada de sustentável e ecologicamente correta, se faz, na realidade, uma condição de alienação dos cidadãos, seja no que Milton Santos considerou como ópio moderno (ou 


\section{O AQUECIMENTO GLOBAL COMO NOVO FUNDAMENTALISMO ECONÔMICO: REFLEXÕES SOBRE O \\ DISCURSO AQUECIMENTISTA \\ Felipe Almeida dos Santos \& Clara Ribeiro Silva}

pós-moderno?), o consumismo como necessidades forjadas, resultado da despolitização do indivíduo e responsável pela máxima "do cidadão imperfeito ao consumidor mais que perfeito" (SANTOS, 2000). Assim, o capital se reproduz e se especializa nas mais diversas localidades do globo, a partir da expansão de um mercado consumidor forjado em uma concepção hegemônica de sociedade, aquela que vê na sustentabilidade ecocapitalista os meios de superação da crise ambiental criada no seio da própria sociedade capitalista.

O segundo, menos visível, mas ainda assim tão perigoso e expressivo, é o viés neomalthusiano do discurso aquecimentista.

Thomas Robert Malthus (1766-1834), economista britânico, considerado o pai da demografia, defendia que a miséria e a pobreza seriam condições necessárias ao pleno desenvolvimento social da humanidade, uma vez que o planeta não abrigaria recursos suficientes para suprir as necessidades de todos seus habitantes. Para Malthus, a população cresce em forma geométrica e a produção de alimentos, em forma aritmética. Assim, não haveria campos férteis suficientes para alimentação de toda a população mundial (DAMIANI, 2004). Mesmo considerados superados os postulados de Malthus e seus discípulos, é comum em momentos de crise do capitalismo a ascensão de discursos que exprimem o malthusianismo, chamados neomalthusianos, em especial a partir da Segunda Guerra Mundial.

Damiani (2004) entende como neomalthusianas as políticas instituídas por organismos internacionais, a exemplo da ONU, UNICEF, Banco Mundial e FMI, destinadas ao controle populacional dos países subdesenvolvidos. Segundo a autora, o problema da superpopulação retoma o debate da necessidade de garantir um controle do crescimento populacional dessas nações, a fim de manter a capacidade de oferta de recursos por parte do planeta. A partir daí surge o caráter neomalthusiano da concepção ambientalista pós Estocolmo 1972, do qual o discurso do aquecimento global é hoje o grande representante. As políticas de mitigação do crescimento das nações subdesenvolvidas e emergentes, seja na aplicação de metas de emissões de poluentes, a aquisição de empréstimos para a adoção de tecnologias limpas e todas as políticas e tratados de controle do crescimento urbano-industrial dos países em desenvolvimento, são nada mais do que tentativas de fazer das desigualdades, condições necessárias a manutenção do desenvolvimento do capitalismo.

Assim, o discurso aquecimentista legitima uma concepção de que as nações subdesenvolvidas, ao se desenvolverem, esgotariam os recursos do planeta, resultando em um 


\section{O AQUECIMENTO GLOBAL COMO NOVO FUNDAMENTALISMO ECONÔMICO: REFLEXÕES SOBRE O \\ DISCURSO AQUECIMENTISTA \\ Felipe Almeida dos Santos \& Clara Ribeiro Silva}

colapso ambiental de proporções globais. Note que a base discursiva não tem como objetivo o questionamento de todo padrão de desenvolvimento do capitalismo em escala planetária, mas sim o de desenvolvimento dos outros, em especial aqueles que de alguma forma possam ameaçar a hegemonia das nações desenvolvidas.

Nessa perspectiva, é mais que necessário desmistificar o aquecimento global como verdade científica, como se fosse um consenso da ciência, isenta e imparcial, criando assim uma falsa ideia de que todas suas afirmações não estão permeadas por interesses políticos, econômicos e geopolíticos. Dessa forma, será possível identificar o discurso aquecimentista como um novo fundamentalismo de base econômica, tornando assim possível representar os reais interesses por trás dessa premissa dita isenta e científica, mas que na realidade é mais uma das formas de manutenção da base hegemônica do capitalismo e seus mecanismos de reprodução das desigualdades.

\section{Considerações finais}

Nascido no interior das lutas populares indígenas e socialistas, o movimento ambientalista, retomado na chamada "contracultura" dos anos 1960 e visto como um importante questionamento e disputa contra o capital, acabou sendo incorporado pelo discurso oficial dos organismos internacionais e nações desenvolvidas, não só como forma de desmobilização, mas como meio de consolidação de novos espaços e mercados para expansão do capital. Assim, a partir do Clube de Roma e da Conferência de Estocolmo 1972, o discurso ambientalista assume novo viés, tornando-se uma importante ferramenta de expansão do capital e de construção de novos mercados consumidores e principalmente, como ferramenta de controle ao crescimento das nações emergentes e subdesenvolvidas.

Nesse processo, a hipótese do aquecimento global, a mais destacada das teses do ambientalismo-ecocapitalista, é tornada verdade científica, seja por meio do financiamento de projetos de pesquisa por grandes grupos empresariais, pela manipulação de dados e utilização de métodos induzidos a legitimar as hipóteses apontadas e principalmente, pelo peso midiático que o tema ganhou, principalmente por sua abordagem alarmista e catastrófica a partir do documentário "Uma Verdade Inconveniente" de Al Gore. 


\section{O AQUECIMENTO GLOBAL COMO NOVO FUNDAMENTALISMO ECONÔMICO: REFLEXÕES SOBRE O \\ DISCURSO AQUECIMENTISTA \\ Felipe Almeida dos Santos \& Clara Ribeiro Silva}

Assim, no terreno fértil do chamado período de acumulação flexível do capitalismo, centrado principalmente em uma ampla rede de serviços e novos espaços produtivos, padrões de consumo são instituídos pelo surgimento de um novo mercado estético-cultural, do qual a hipótese do aquecimento global, estratégia de consolidação do chamado desenvolvimento sustentável, assume condição de novo fundamentalismo, seja por seu potencial de impor um novo modelo de consumo, o chamado consumo sustentável, seja no plano da aplicação de projetos tecnológicos, energéticos e de infraestrutura, ou no que se refere a bens de consumo mais gerais, tais como mercadorias e serviços e também, no estabelecimento de uma geopolítica global de controle ao crescimento das nações emergentes e subdesenvolvidas, numa nova manifestação do neomalthusianismo que busca legitimar as desigualdades globais sob o álibi da incapacidade do Planeta de prover recursos para o pleno desenvolvimento de todas as nações e seus habitantes.

Por fim, é necessário desconstruir os argumentos que tentam fazer da retórica científica uma espécie de verdade absoluta e inquestionável, principalmente os que se manifestam imparciais, mas que na realidade, assim como o discurso aquecimentista, assumem condição de manifestação fundamentalista dos interesses geopolíticos e econômicos de grupos empresariais internacionais e nações desenvolvidas.

\section{Referências Bibliográficas}

BAPTISTA, G.M.M. Aquecimento global: ciência ou religião? Brasília: Hinterândia Editorial, 2009.

DAMIANI, A.L. População e geografia. 8.ed. São Paulo: Contexto, 2004.

IPCC. Contribuição do Grupo de Trabalho I ao Quarto Relatório de Avaliação do Painel Intergovernamental sobre Mudança do Clima, 2007. Disponível em: $<$ https://www.ipcc.ch/pdf/reports-nonUN-translations/portuguese/ar4-wg1-spm.pdf Acesso em $23 / 08 / 2016>$

HARVEY, D. A condição pós-moderna. 25.ed. São Paulo: Edições Loyola, 2014.

LINO, G.L. A fraude do aquecimento global: como um fenômeno natural foi convertido numa falsa emergência mundial. $3^{\circ}$ edição. Rio de Janeiro: Capax Dei editora, 2009

LÖWY, M. O que é ecossossialismo? 2. Ed. São Paulo: Cortez, 2014. 
MARUYAMA, S. Aquecimento Global? Tradução de Kenitiro Suguio. São Paulo: Oficina de Textos, 2009.

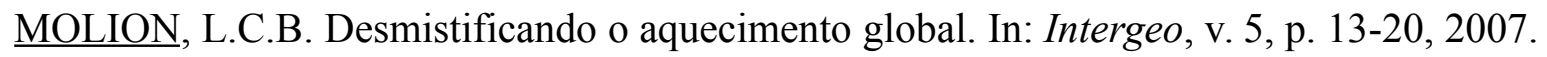

MOLION, L.C.B. Aquecimento global: uma visão crítica. In: Revista brasileira de climatologia, v. 3/4, p. 7-24, 2008.

MONTEIRO, C.A.F. Teoria e Clima Urbano. São Paulo, Instituto de Geografia da USP, 1976. Série "Teses e Monografias" n²5.

PORTO-GONÇALVES, C.W. Os (des)caminhos do meio ambiente. 15.ed. São Paulo: Contexto, 2011.

RIBEIRO, W.C. A ordem ambiental internacional. 3. ed. São Paulo: Contexto, 2014. 